Original Research Article

\title{
Drug prescribing pattern in surgical wards of a tertiary care hospital in Western part of India
}

\author{
Khyati M. Patel ${ }^{1}$, Shilpa D. Jadav ${ }^{2 *}$, Shailesh P. Parmar ${ }^{2}$, Hiren Trivedi²
}

\begin{abstract}
${ }^{1}$ Drug Safety Physician, APCER Life Science, Mondeal Heights, Iscon Cross Road, S.G.

Highway, Ahmedabad, Gujarat, India

${ }^{2}$ Department of Pharmacology,

M.P. Shah Govt. Medical

College, Jamnagar, Gujarat, India
\end{abstract}

Received: 24 May 2018

Accepted: 26 June 2018

\section{*Correspondence to: \\ Dr. Shilpa D. Jadav, \\ Email: drshilpa79@ \\ rediffmail.com}

Copyright: (C) the author(s), publisher and licensee Medip Academy. This is an openaccess article distributed under the terms of the Creative Commons Attribution NonCommercial License, which permits unrestricted noncommercial use, distribution, and reproduction in any medium, provided the original work is properly cited.

\begin{abstract}
Background: In surgical wards, drugs are required to manage pain, nausea, vomiting, infections, etc. A growing number of pharmaceutical products are available in present era. Irrational prescribing of drugs is prevalent worldwide. Drug utilization study can be used to assess prescribing patterns. Authors undertook this study to determine current practice of prescribing in surgical wards of the hospital.

Methods: Authors conducted observational, noninterventional, descriptive study among patients admitted in surgical wards for one year. Authors have analysed collected data of 604 patients using descriptive statistics to determine utilization pattern of drugs and drug use indicators.

Results: Appendicitis (14.9\%) followed by hernia (10.6\%) were leading diseases for admission. Mean duration of stay was 7.44. Average number of drugs in a prescription was 8.94. Antibiotics (32.07\%), analgesics (17.11\%) and antacids $(16.09 \%)$ were leading drug groups prescribed. Amikacin $(5.81 \%)$ followed by metronidazole $(5.30 \%)$ and ciprofloxacin $(5.19 \%)$ were commonly prescribed antimicrobial drugs. Tramadol $(5.31 \%)$ and pantoprazole $(7.17 \%)$ were leading drugs prescribed from analgesics and antacids respectively. All prescriptions had at least one injectable drug. At least one antibiotic was present in $92.05 \%$ prescriptions. Majority of drugs $(87.27 \%)$ were prescribed by generic names. Proportion of drugs prescribed from essential medicine list was $84.22 \%$.

Conclusions: Polypharmacy and injectable drug prescribing were common in practice. There is a scope for improving such prescribing practices among practitioners. Use of multiple antibiotics should be avoided whenever possible and usage should be evidence based.
\end{abstract}

Keywords: Drug utilization study, Drug use indicator, Surgical ward

\section{INTRODUCTION}

Drug utilization study is "the marketing, distribution, prescription and use of a drug in society with special emphasis on resulting medical, social and economic consequences". ${ }^{1}$ Main aim of such study is to promote rational use of drugs in society. Irrational prescribing habits are present worldwide. More than $50 \%$ of all medicines are prescribed, dispensed or sold inappropriately, while $50 \%$ of patients fail to take them correctly in world. Moreover, about one-third of the world's population lacks access to essential medicines. ${ }^{2}$ Antibacterial agents are prescribed even if not indicated, inappropriate in terms of drug selection or dosage or therapeutic basis. Such use of antimicrobial agents may cause number of problems including emergence of antimicrobial resistant bacteria. ${ }^{3}$ Many times, injectable drugs are given even if alternative oral drug is available. A growing number of pharmaceutical products are available and there has been an increase in both the consumption of the drugs and in expenditure on them. In country like India, where resources are limited, rational prescribing is important. However, before suggesting any change, it is 
necessary to evaluate the existing base line practice which can be done using data on prescriptions and prescribing practices with the help of a drug utilization study. ${ }^{4}$ Feedback to doctors regarding their current prescribing practice compared to standard therapy or guideline improves prescribing practice among them.

In surgical wards, drugs are required to manage pain, nausea, vomiting, infections, etc. Salman MT et al, in his study of prescribing practices among patients of surgical wards found that proportion of drugs prescribed from essential medicine list was low with an average prevalence of more than 2 broad spectrum antibiotics given unnecessarily along with extensive use of other drugs. ${ }^{5}$ Thus it is necessary to sensitize surgeons about prescribing needed drugs from essential medicine list with generic names and cost consideration. Also, there is a clear need for the development of prescribing guidelines and educational initiatives to encourage the rational and appropriate use of drugs in surgery. We decided to undertake this study to investigate the current situation in surgical wards of our hospital.

\section{METHODS}

This prospective, observational, descriptive study was carried out after approval from institutional ethics committee of the institute. We used a sample consisting 604 patients. Duration of study was one year from April 2015 to March 2016. In this study, we included indoor patients of both sex including pregnant and lactating mother admitted in general surgery wards of the institute. Patients referred to higher centre, died before discharge, absconded or discharged against medical advice were excluded. The diagnosis and line of treatment to be given was decided by surgeon in charge of the ward. Written informed consent was taken from patients fulfilling study criteria. After interview of patient and review of case paper data regarding demographic details, clinical status, operative procedure, medication prescribed till discharge result of culture and sensitivity test, etc. were recorded in case record forms. The data collected was analysed with the help of MS excel using descriptive statistics to determine drug use indicators and utilization pattern of drugs. National essential medicine list 2015 was used for the reference to evaluate percentage of drugs prescribed from essential medicine list. ${ }^{6}$

\section{RESULTS}

We have analysed data of 604 prescriptions. Majority of patients were from 20 to 50 years age group $(52.65 \%)$ with mean age was $39.22 \pm 19.62$ years. Proportion of male to female was 1.54:1 in this study. Duration of admission for majority of patients $(53.64 \%)$ was 5-10 days. Mean duration of stay was $7.44 \pm 4.82$ days (Table 1 ).

Table 2 shows morbidity pattern among patients. Appendicitis (14.9\%) followed by hernia (10.6\%) were leading diseases for admission in this study. Out of total operative procedures; leading operative procedures were appendicectomy (21\%), cyst or lipoma excision (17\%), hernia repair and meshplasty (16\%), laprotomy (13\%) and amputation (10\%). Other operative procedures were debridement, circumcision, hydrocele, nephrolithotomy or pyelolithotomy and anorectal surgery.

Table 1: Demographic characteristics of patients.

\begin{tabular}{|ll|}
\hline Characteristics & No. of patients \\
\hline Age (years) & \\
\hline Less than 20 years & $122(20.2 \%)$ \\
\hline 20-50 years & $318(52.65 \%)$ \\
\hline More than 50 years & $164(27.15 \%)$ \\
\hline Sex & \\
\hline Male & $366(60.60 \%)$ \\
\hline Female & $238(39.40 \%)$ \\
\hline Duration of Stay & $178(29.47 \%)$ \\
\hline Less than 5 & $324(53.64 \%)$ \\
\hline 5-10 days & $92(15.23 \%)$ \\
\hline 11-20 days & $6(0.90 \%)$ \\
\hline 21-30 days & $4(0.66 \%)$ \\
\hline More than 30 days & \\
\hline
\end{tabular}

Table 2: Distribution of patients as per disease.

\begin{tabular}{|ll|}
\hline Disease & $\%$ of patients \\
\hline Appendicitis & $14.9 \%$ \\
\hline Hernia & $10.6 \%$ \\
\hline Abdominal pain & $6.3 \%$ \\
\hline Abscess & $6.6 \%$ \\
\hline Cystitis & $7.9 \%$ \\
\hline Renal/bladder stone & $5.6 \%$ \\
\hline Brest lump/fibroadenoma & $5.3 \%$ \\
\hline Cellulitis & $6.3 \%$ \\
\hline Cyst & $3.3 \%$ \\
\hline Diabetic foot & $3.6 \%$ \\
\hline Lyphadenopathy inguinal & $2.2 \%$ \\
\hline Phimosis & $2.6 \%$ \\
\hline Renal colic & $2.2 \%$ \\
\hline
\end{tabular}

In this study, total 5400 drugs were prescribed. Antibiotics (32.07\%), analgesics (17.11\%) and antacids (16.09\%) were leading drug groups prescribed in this study.

Table 3 show prescribing patterns of drug groups. Among antimicrobial agents, amikacin $(5.81 \%)$ was the most common prescribed drug followed by metronidazole $(5.30 \%)$ and ciprofloxacin $(5.19 \%)$. Tramadol $(5.31 \%)$ followed by diclofenac $(4.46 \%)$ and paracetamol (3.26\%) were first three commonly prescribed analgesic drugs. Among antacid drugs, pantoprazole $(7.17 \%)$ followed by famotidine $(4.3 \%)$ and ranitidine $(2.35 \%)$ were first three commonly prescribed drugs. Out of total drugs, $14.28 \%$ drugs were parenteral fluids. Dextrose normal saline $(4.33 \%)$, ringer's lactate $(3.44 \%)$ were most commonly used parenteral fluids. Table 3 shows prescribing patterns 
of various drugs. Table 3 shows prescribing pattern of various drugs.

Of all drugs, $68.24 \%$ drugs were prescribed in injectable form. Average number of drugs prescribed was 8.94. In this study, a prescription contained minimum of four drugs and maximum of thirteen drugs. All prescriptions had at least one injectable drug. At least one antibiotic was present in $92.05 \%$ prescriptions with range of 0 to 7 . Nearby one third (32\%) prescription have 3 antibiotics. Table 4 shows drug use indicators.

Table 3: Prescribing patterns of various drugs.

\begin{tabular}{|c|c|c|}
\hline Drugs & No. of drugs prescribed & Percentage \\
\hline Antimicrobial agents & 1732 & 32.07 \\
\hline Amikacin & 314 & 5.81 \\
\hline Metronidazole & 286 & 5.30 \\
\hline Ciprofloxacin & 280 & 5.19 \\
\hline Ceftriaxone & 280 & 5.19 \\
\hline Amoxicillin + Clavulanic acid & 138 & 2.56 \\
\hline Cefotaxime & 85 & 1.57 \\
\hline Cefixime & 73 & 1.35 \\
\hline Piperacillin + Tazobactam & 67 & 1.24 \\
\hline Other antibiotics* & 209 & 3.87 \\
\hline Analgesic and antispasmodic drugs & 924 & 17.11 \\
\hline Tramadol & 287 & 5.31 \\
\hline Diclofenac & 241 & 4.46 \\
\hline Paracetamol & 176 & 3.26 \\
\hline Hyoscine butyl bromide & 106 & 1.96 \\
\hline Ibuprofen & 102 & 1.89 \\
\hline Others $* *$ & 12 & 0.22 \\
\hline Antacid drugs & 869 & 16.09 \\
\hline Pantoprazole & 387 & 7.17 \\
\hline Famotidine & 232 & 4.30 \\
\hline Ranitidine & 127 & 2.35 \\
\hline Omeprazole & 107 & 1.98 \\
\hline Rabeprazole & 16 & 0.30 \\
\hline Parenteral fluids & 771 & 14.28 \\
\hline Dextrose normal saline solution & 234 & 4.33 \\
\hline Ringer's Lactate solution & 186 & 3.44 \\
\hline Dextrose $5 \%$ solution & 133 & 2.46 \\
\hline Dextrose $25 \%$ solution & 78 & 1.44 \\
\hline ISO-M solution & 74 & 1.37 \\
\hline Others (Normal saline, ISO-P solution) & 66 & 1.22 \\
\hline Vitamins and minerals & 422 & 7.81 \\
\hline Multivitamin / B-Complex tablets & 153 & 2.83 \\
\hline Vitamin $\mathrm{C}$ tablets & 123 & 2.28 \\
\hline Tablet folic acid & 76 & 1.41 \\
\hline Others vitamins and minerals $* * *$ & 70 & 1.30 \\
\hline Antiemetic drugs & 342 & 6.33 \\
\hline Ondansetron & 308 & 5.70 \\
\hline Domperidone & 26 & 0.48 \\
\hline Metoclopramide & 8 & 0.15 \\
\hline Other drugs $* * * *$ & 340 & 6.30 \\
\hline
\end{tabular}

* Other antibiotics includes Cloxacillin, Crystalline penicillin, Amoxicillin, Nafcillin, Cefoperazone, Ceftriaxone + Sulbactam, Meropenem, Doxycycline, Gentamicin, Azithromycin, Linezolid, Albendazole, Diethylcarbamazine, Sulfamethoxazole with trimethoprim

**Other analgesic and antispasmodic drugs are Diclofenac, paracetamol, serratiopeptidase (Diclo+sp tablets) combination and Drotaverine ***Other vitamins and minerals - Multivitamin inj., Ferrous sulphate, Vitamin K inj, Calcium

****Others includes less frequently prescribed drugs from various drug groups - Tetanus toxoid, Diazepam, Biscodyl, Carbimazole, Furosamide, Cetrizine, Deriphyllin, Drotaverine, Tamsulosin, Urodeoxycholic acid, Lignocaine, Bupivacaine, Atropine 
Table 4: Summary of drug use indicators.

\begin{tabular}{|ll|}
\hline $\begin{array}{l}\text { Average number of drugs prescribed } \\
\text { \% of encounters with an antibiotic } \\
\text { prescribed }\end{array}$ & $\mathbf{8 . 9 4}$ \\
\hline \% of encounters with injections prescribed & $100.00 \%$ \\
\hline \% of drugs prescribed by generic name & $87.27 \%$ \\
\hline $\begin{array}{l}\text { \% of drugs prescribed from essential } \\
\text { medicine list }\end{array}$ & $84.22 \%$ \\
\hline Average no. of antibiotic per prescription & 2.86 \\
\hline Average no. of injection per prescription & 6.10 \\
\hline $\begin{array}{l}\text { Availability of essential medicine list or } \\
\text { formulary }\end{array}$ & Yes \\
\hline Key drugs available & $86.18 \%$ \\
\hline
\end{tabular}

\section{DISCUSSION}

In this study, $60.60 \%$ were male and $39.40 \%$ were female. Similar male preponderance was reported by other studies. ${ }^{7-9}$ Majority of patients $(52.64 \%)$ were between age group of 20-50 years. The finding is in consonance with other studies. ${ }^{7,10,11}$ One of the possible reason is that productive age group is actively involved in socioeconomic activities, making them vulnerable to diseases, which may need surgical interventions. ${ }^{7}$ Disease patterns in this study were appendicitis $(14.9 \%)$ followed by hernia $(10.6 \%)$, cystitis $(7.9 \%)$ and other conditions. Our findings are in consonance with other studies. ${ }^{9,12}$ However in study by Sharma et al, renal stone was leading operative procedure. ${ }^{7}$ A wide spectrum of clinical diagnoses was observed in this study. Region wise morbidity pattern may differ. Other possible reason may be difference in health care facility of the hospital. Thus, observed disease pattern may differ from other study. In this study, majority of patients had duration of stay less than 10 days. The mean duration of stay was 7.44 days. This finding are in consonance with other studies. ${ }^{8,10}$

In this study, most commonly prescribed groups of drugs were antibiotics (32\%) followed by analgesic (17\%) and antacids (16\%). Prescribing pattern of drug groups is in consonance with other studies. ${ }^{5,13}$ Antimicrobial agents are very important class of drugs essential in treating or preventing infections in patients. Patients in surgical wards may develop infections post-surgery; many of the infections may be due to highly virulent bacteria. The use of antibiotics in surgical patients for prophylaxis and treatment of infections is a justifiable practice. However, its use should be judicious which requires regular review of chosen regimen on the grounds of efficacy, toxicity, cost and other aspects to maximize the benefits to the patient. ${ }^{10}$

The most common drug group was antibiotics (32\%) in this study. Commonly prescribed antibiotics were amikacin $(5.81 \%)$ followed by metronidazole $(5.30 \%)$, ciprofloxacin $(5.19 \%)$ and ceftriaxone $(5.19 \%)$. Amikacin was $2^{\text {nd }}$ in more commonly prescribed drugs in this study. We found it in $314(51.99 \%)$ encounters. Khade et al, observed that ciprofloxacin and metronidazole were most commonly used antibiotics. ${ }^{11}$ In study by Vadajiya et al, metronidazole and ciprofloxacin were two most commonly prescribed antibiotics. ${ }^{14}$ Study by Salman et al, showed major use of amikacin. ${ }^{5}$ Amikacin is potentially ototoxic and nephrotoxic. The risk of nephrotoxicity is greater in patients with impaired renal function and in those who receive high doses or prolonged therapy. Also, to reduce the development of drug-resistant bacteria and maintain the effectiveness, amikacin should only be used to treat or prevent infections that are proven or strongly suspected to be caused by susceptible bacteria.

In present study, one third of prescriptions (32\%) were with three antibiotics. Average number of antibiotics per prescription was 2.86. Other studies showed similar results. ${ }^{5,8,14}$ The higher number of antibiotics per patient indicates that more and more antibiotics were used for prophylaxis purpose rather than definitive treatment purpose, more as a blanket therapy to prevent any or all types of infections. This not only leads to the increased cost of therapy, but also to increased incidence of adverse drug reactions and to the selection of drug resistant bacterial strains. ${ }^{8}$

Analgesics and antispasmodic drugs (17.11\%) were second most common group prescribed in this study. Tramadol $(5.31 \%)$ was the most commonly used analgesic. Authors found it in $287(47.52 \%)$ prescription. It was $4^{\text {th }}$ in commonly prescribed drugs in this study. Analgesic drugs are required to manage pain due to disease or operative procedures. Patients in surgical wards may have inflammatory pain, postoperative pain or many times visceral pain. Opioid analgesics like tramadol can be useful to manage such pain. Tramadol has advantage over other opioids likeless chances of respiratory depression, low potential for development of tolerance, dependence and abuse. ${ }^{15}$ Diclofenac $(4.46 \%)$ was the second most common analgesic. Our study findings are comparable to observation in other study. ${ }^{5}$ However in study by Bhansali et al, diclofenac was the most commonly prescribed analgesic drug. ${ }^{8}$

The third most common drug group was antacid (16.09\%) in this study. Pantoprazole $(7.17 \%)$ followed by famotidine $(4.30 \%)$ were two commonly prescribed antacids. Pantoprazole was the most common drug prescribed in this study. We found it in $387(68.07 \%)$ prescriptions. Pantoprazole was the most extensively prescribed drug among antacids in similar study. ${ }^{5}$ However, in study by Bhansali et al, the most common antacid drug was ranitidine. ${ }^{8}$ Antacids are given before surgery to prevent aspiration. Proton pump inhibitors are more effective in suppressing acid output than other antacids.

Parenteral fluids prescribed were $14.28 \%$ of all drugs. Dextrose normal saline $(4.33 \%)$ followed by ringer's lactate $(3.44 \%)$ and dextrose $(2.46 \%)$ were first three common fluids prescribed. This finding is in consonance with other studies. ${ }^{8,16}$ Parenteral fluids are required for fluid and electrolytes replacement, nutrition and as a vehicle for drug infusion. Parenteral fluids prescribing increases injectable 
formulation in a prescription, number of drugs in a prescription and cost.

Out of antiemetic drugs $(6.70 \%)$, the most commonly used antiemetic was ondansetron $(5.70 \%)$ as it is highly effective and possesses low side effect profile. It was present in 308 $(50.99 \%)$ encounters and $3^{\text {rd }}$ in more commonly prescribed drugs in this study. The finding is in consonance with other study. ${ }^{8}$ This drug was mainly prescribed as brand name (zoffer) in prescription.

In this study, polypharmacy was observed as average number of drugs per prescription was 8.94. The finding is comparable with other studies. ${ }^{8,13,17}$ Polypharmacy is relevant as patients in surgical wards require drugs for treatment of specific condition as well as for prophylaxis. However, it may also be responsible for more adverse drug reaction, drug interaction and increased cost of therapy. It is essential to keep a balance between the number of drugs and effective pharmacotherapy. ${ }^{18}$

Drugs prescribed by generic name were $87.27 \%$. Other studies showed similar findings. ${ }^{7,13}$ However, studies by Bansali et al, and Khade et al, showed lower percentage of drugs prescribed by generic names. ${ }^{8,11}$ All encounters contained an injection prescribed, may be an injectable antibiotic, an injectable analgesic or intravenous fluid. This was comparable to the finding observed in other studies. ${ }^{8,11}$ Average number of injection per prescription including parenteral fluid was 6.10 .

Increased number of injections leads to increase in cost of treatment, patient morbidity and negatively influenced the WHO recommended prescribing indices. In present study, percentage of drugs prescribed from national list of essential medicine 2015 was $84.22 \% .^{6}$ Other study had similar result. ${ }^{7}$ However, Bansali et al, observed lower percentage of drugs prescribed from national list of essential medicine. ${ }^{8}$

Despite some limitations of our study like single centre study and relatively small sample size, we can conclude that there is a scope for improving prescribing pattern among practitioners. It is advisable to avoid drugs merely for blanket prophylactic therapy. Whenever possible, we suggest decreasing injectable drugs prescribing practice. Drugs should be prescribed from essential medicine list by their generic names with due cost consideration.

\section{ACKNOWLEDGEMENTS}

Authors would like to thank to all staff members of surgical wards, G. G. G. Hospital for their cooperation for successful completion of this study.

Funding: No funding sources Conflict of interest: None declared

Ethical approval: The study was approved by the Institutional Ethics Committee

\section{REFERENCES}

1. World Health Organization. Introduction to Drug Utilization Research. Geneva: World health organization; 2003.

2. World Health Organization. Promoting rational use of medicines: core components. Geneva: World health organization; 2002.

3. Raveh D, Levy Y, Schlesinger Y, Greenberg A, Rudensky B, Yinnon AM. Longitudinal surveillance of antibiotic use in the hospital. Q J Med 2001;94:14152.

4. Bhabhor P, Hotchandani H. An Antibacterial Drug Utilization Study at Surgical Units of Shree Sayaji General Hospital, Vadodara, Gujarat, India. The Internet J Pharmacol. 2012;10:2/16.

5. Salman MT, Akram MF, Rahman S, Khan FA, Haseen MA, Khan SW. Drug prescribing pattern in surgical wards of a teaching hospital in North India. Ind $\mathrm{J}$ the Practis Doc. 2008;5(2):5-8.

6. Ministry of Health and Family Welfare Government of India. National List of Essential Medicines; 2015. Available http://cdsco.nic.in/WriteReadData/NLEM-

2015/NLEM,\%202015.pdf. Accessed 20 October 2016.

7. Sharma N, Bhargava M, Chaudhary V, Advani U, Jain A, Bansal A. A prospective study of drug utilization pattern in surgery department in a tertiary care teaching hospital in Rajasthan. UJP 2014;03(02):4750.

8. Bhansali NB, Gosai TR, Dholaria NK, Suthar SD, Chacko J, Chavda DA, et al. Drug utilization study in post-operative patients in surgical ward of a tertiary hospital attached with medical college. Der Pharmacia Lettre. 2013;5(1):251-7.

9. Venkateswarlu B, Swapna Y, Florence S, Lakshmi Santoshi M, Swetha T, Prathyusha K, et al. Drug utilization study of antibiotics in surgical ward of a tertiary care hospital. Inte $\mathrm{J}$ Chem and Pharmaceu Scienc. 2015;6(1):106-13.

10. Patil S, Padma L, Veena DR, Shanmukananda P. Drug utilization study of antimicrobials in post-operative wards in a teaching hospital. Int Res J Pharm App Sci. 2012;2(5):56-9.

11. Khade A, Bashir M, Sheethal A. Prescription Pattern in the Department of Surgery in A Tribal District Hospital of Andhra Pradesh, India. Ann Med Health Sci Res 2013;3(3):438-41.

12. Kumar BA, Adiveni T, Manna PK, Kumar M, Sundresh D. Studies on antibiotic prescribing pattern in surgical ward of department of surgery at rajah muthiah medical college hospital. World J Pharma and Pharmaceut Scien. 2014;3(7):832-71.

13. Mondal S, Pramani S, Mallick B, Sengupta M, Niyogi S, Chaudhuri P. A Drug Utilization Study in the Indoor Ward of the Surgery Department of a Tertiary Care Hospital of Eastern India. IOSR J Den and Med Scienc. 2015:14(10):42-7. 
14. Vadajiya S, Naik V, Mevada A. A Study of AntiMicrobial Drug Utilization Pattern and Appropriateness in The Surgical Units of Civil Hospital, Ahmedabad; Int $\mathbf{J}$ Pure App Biosci. 2014;2(3):77-82.

15. Chaturvedi S, Chaturvedi A. Postoperative pain and its management. Indian J Crit Care Med. 2007;11:204-11.

16. Gyawali S, Shankar PR, Saha A, Mohan L. Study of prescription of injectable drugs and intravenous fluids to inpatients in a teaching hospital in Western Nepal. MJM. 2009;12:13-20.

17. Sharma N, Bhargava M, Mahawar D, Paeakh R, Sharma D. Usage of Antibiotics in postoperative patients in tertiary care teaching hospital in India. IJPRB. 2014;3(2):99-105.

18. Mohammed SS, Sreenath MK, Vishnu VG, Jose F, Siraj ST, Anand VP. The Prevalence of Polypharmacy in South Indian Patients: A Pharmacoepidemiological Approach. Ind J Pharma Practi. 2012;5(3):40-4.

Cite this article as: Patel KM, Jadav SD, Parmar SP, Trivedi $\mathrm{H}$. Drug prescribing pattern in surgical wards of a tertiary care hospital in Western part of India. Int J Basic Clin Pharmacol 2018;7:1587-92. 